\title{
Classificação morfológica da glândula prepucial do Nasua nasua (quati)
}

\author{
Bruno Machado Bertassoli ${ }^{1 *}$ \\ Amilton Cesar dos Santos ${ }^{1}$ \\ Naira Caroline Godoy Pieri ${ }^{1}$ \\ Vanessa Cristina de Oliveira ${ }^{1}$ \\ Celina Almeida Furlanetto Mançanares² \\ Ana Flávia de Carvalho ${ }^{3}$

\begin{abstract}
${ }^{1}$ Faculdade de Medicina Veterinária e Zootecnia, Departamento de Cirurgia PPG em Anatomia dos Animais Domésticos e Silvestres, Universidade de São Paulo - USP Avenida Professor Dr. Orlando Marques de Paiva, CEP 05508-270, São Paulo - SP, Brasil

${ }^{2}$ Faculdade de Zootecnia e Engenharia de Alimentos - USP, Pirassununga - SP, Brasil ${ }^{3}$ Centro Universitário da Fundação de Ensino Octávio Bastos, São João da Boa Vista - SP, Brasil

*Autor para correspondência

bbertassoli@bol.com.br
\end{abstract}

Submetido em 01/02/2011

Aceito para publicação em 05/05/2011

\section{Resumo}

A proposta desta pesquisa é descrever a glândula prepucial do Nasua nasua. Utilizaram-se oito quatis provenientes do Criatório Científico Cecrimpas (Unifeob); as glândulas prepuciais foram analisadas, dissecadas e descritas macro e microscopicamente, visando estabelecer sua classificação morfofuncional para, assim, poder compará-las com as de outras espécies já descritas na literatura. Amostras de tecido glandular foram coletadas, coradas (Hematoxilina e Eosina, Azul Toluidina, e Picrosirius) e analisadas através da microscopia de luz. Todos os resultados foram compilados e fotodocumentados. Na espécie citada, essa glândula tem como principal função a demarcação territorial e está situada na porção prepucial do mesmo modo que nos javalis. Em outros animais, como primatas, cervídeos e roedores, essas glândulas demarcatórias estão localizadas em diferentes regiões anatômicas, como entre os olhos, no metatarso, nas áreas perianais e esternais. Em nosso resultado das medidas biométricas, obtivemos como média $3,8 \pm 1,41 \mathrm{~cm}$ de largura, 3,15 $\pm 0,93 \mathrm{~cm}$ de altura e $10,26 \pm 1,89 \mathrm{~cm}$ de circunferência, e essa glândula foi histologicamente classificada como do tipo tubuloalveolar, com secreção holócrina.

Palavras-chave: Glândula prepucial, Morfologia, Quati

\section{Abstract}

Morphologic classification of the Nasua nasua (coati) preputial gland. The proposal of this research is to describe the Nasua nasua preputial gland. Eight coatis from the Scientific Breeding Center Cecrimpas (Unifeob) were used; the preputial glands were analyzed, dissected, and described both macro and microscopically, aiming to establish their morphofunctional classification and, this way, they could be compared to the other 
species already described in the literature. Samples of glandular tissue were collected, stained (Hematoxylin and Eosin, Toluidine Blue, and Picrosirius), and analyzed through light microscopy. All results were collected and photodocumented. In the referred species, this gland has as its main function the territorial demarcation and it is located in the preputial portion as in wild boars. In other animals, such as primates, deer, and rodents, these demarcating glands are located in different anatomic regions, as between the eyes, in the metatarsus, in the perianal and sternal areas. Our results of the biometric reading showed the average values of $3.8 \pm 1.41 \mathrm{~cm}$ width, $3.15 \pm 0.93 \mathrm{~cm}$ height, and $10.26 \pm 1.89 \mathrm{~cm}$ circumference, and this gland was histologically classified as pertaining to the tubuloalveolar type, with holocrine secretion.

Key words: Coati, Morphology, Preputial gland

\section{Introdução}

No Brasil, quatro espécies de procionídeos são encontradas, sendo elas: Nasua nasua (quati), Procyon cancrivorus (mão-pelada), Potos flavus (jupara) e Bassaricyon gabbi (olingo) (BEISIEGEL, 2001).

O quati pertence ao filo Chordata, a classe Mammalia, à ordem Carnívora e a família Procyonidae. Pode medir $43-66 \mathrm{~cm}$ de comprimento e mais $22-69 \mathrm{~cm}$ de cauda, também pode chegar a $30,5 \mathrm{~cm}$ de altura e até $11 \mathrm{~kg}$, reproduz uma ninhada por ano e variando de dois a sete filhotes que com cinco semanas de idade deixam o ninho e se juntam ao grupo (ZELLER, 1999).

Esta espécie vive em grandes grupos formados por fêmeas e machos jovens, habitualmente no final da primavera, o macho adulto dominante aproxima-se do grupo e após o acasalamento este é banido pelas fêmeas (BEISIEGEL, 2001). Segundo Franciolli (2007) o quati, apresenta uma glândula próxima ao pênis, que esta diretamente relacionada ao período de reprodução, segundo este autor ela é utilizada como uma forma de demarcação de áreas territoriais, através de secreção glandular em substratos como solo e troncos. Animais, como primatas, cervídeos e roedores possuem glândulas demarcatórias em diferentes localizações anatômicas, como regiões orbitais (Cervos) e na base da cauda (Lobos e Raposas) (HICKMAN JR. et al., 2004; DELLMANN; WROBEL, 1982).

As glândulas prepuciais de quatis foram analisadas, macro e microscopicamente visando estabelecer sua classificação morfofuncional e compará-las com de outras espécies descritas na literatura consultada. Esta glândula é uma estrutura morfológica muito importante, pois através dela podemos inferir sobre o comportamento destas espécies da fauna brasileira, tendo em vista a íntima relação desta glândula com o comportamento e ciclo reprodutivo.

\section{Material e Métodos}

Para a descrição morfológica da glândula de demarcação de território prepucial de Nasua nasua, foram utilizados oito animais machos, adultos, provenientes do Criatório Científico (CECRIMPAS) - UNIfeob autorizado pelo IBAMA Processo: $n^{\circ}$ 02027.003731/04-76. O projeto obteve aprovação da Comissão de Ética do Curso de Medicina Veterinária (UNIfeob), com o n ${ }^{\circ} 2009.03$.

Os animais foram pré-anestesiados com acepran ${ }^{\circledR}$ (acepromazina) $0,05 \mathrm{mg} / \mathrm{kg}$ (IM) seguido de indução anestésica com telazol ${ }^{\circledR}$ (Cloridrato de tiletamina $125 \mathrm{mg}$ mais Cloridrato de zolazepan $125 \mathrm{mg}$ ) $20 \mathrm{mg} / \mathrm{kg}$ (IV), em seguida as glândulas foram investigadas, fotografadas e mensuradas, e posteriormente, eutanasiados após alcançar o plano anestésico profundo com injeção de Cloreto de Potássio 19,1\% (10ml) via intracardíaca.

Para análise macroscópica a glândula de cheiro foi identificada, mensurada e em seguida dissecada e fixada em solução de formaldeído a $10 \%$.

A glândula foi mensurada através de paquímetro de precisão da marca Mitotoyo ${ }^{\circledR}$ obedecendo aos seguintes parâmetros: altura desde sua inserção proximal ao abdome até sua porção distal do abdome; largura e diâmetro que foi medido com auxilio de um cordonê posteriormente estendido sobre sistema métrico. Os dados obtidos da biometria foram compilados em tabelas.

As glândulas dos respectivos animais foram fotografadas através de câmera digital Sony Mavica 3.2 MP. 
Para a análise microscópica, foram coletados fragmentos glandulares abrangendo todos os estratos teciduais. Os fragmentos foram identificados e processados pelas técnicas rotineiras de histologia. Os blocos e suas diferentes porções foram cortados em micrótomo Leica RM 2165, com espessura média de $5 \mu \mathrm{m}$ posteriormente corados com Hematoxilina Eosina, Azul de Toluidina e Picrosírius (JUNQUEIRA; CARNEIRO, 2008). O material foi analisado, mapeado, e fotografado através de fotomicroscópio Coleman com maquina digital Mavica 3.2 MP. As técnicas usadas seguiram os padrões descritos por Tolosa et al. (2003).

Os resultados foram compilados e descritos segundo as determinações do International Committee on Veterinary Gross Anatomical Nomenclature (2005).

\section{Resultados e Discussão}

Em nossos estudos a única glândula evidenciada macroscopicamente estava localizada na região prepucial, da mesma vai forma que Herrero et al. (2001) evidenciaram nos javalis, porém foram investigadas outras regiões com a finalidade de identificar outras glândulas de cheiro, mas, não foi possível notar uma grande variedade quanto à localização desta glândula, diferente do descrito por Hickman Jr. et al. (2004) onde afirmam que as glândulas odoríferas estão presentes em quase todos os mamíferos, tendo localizações e funções bastante distintas, situam-se nas regiões orbital, metarsal e interdigital (nos cervos), entre os olhos e nas laterais do focinho (nos octonídeos e marmotas), no pênis (no rato, castores e diversos canídeos), base da cauda (nos lobos e raposas), na parte de traz da cabeça (dromedário) e na região anal (gambás, Mustela sp. e doninhas).

As glândulas prepuciais foram classificadas de glândulas de cheiro, pois liberam sinais químicos que são provenientes de substâncias secretadas e esta é uma forma de comunicação que ocorre aparentemente em resposta a estímulos auditivos, visuais e olfativos provenientes do meio ambiente geralmente durante encontros sexuais e enfrentamentos entre grupos como afirmam Herrero et al. (2001) e Franciolli et al. (2007). Ellenport (1986) cita que nos carnívoros domésticos, o prepúcio forma uma bainha completa ao redor da parte distal do pênis. A camada externa é o tegumento comum (cútis, pele e anexos cutâneos) e as camadas internas são finas, de coloração avermelhada e isentas de glândulas. Do mesmo modo, observamos que nos quatis a camada peniana está intimamente inserida à parte longa da glande e frouxamente ao bulbo da glande.
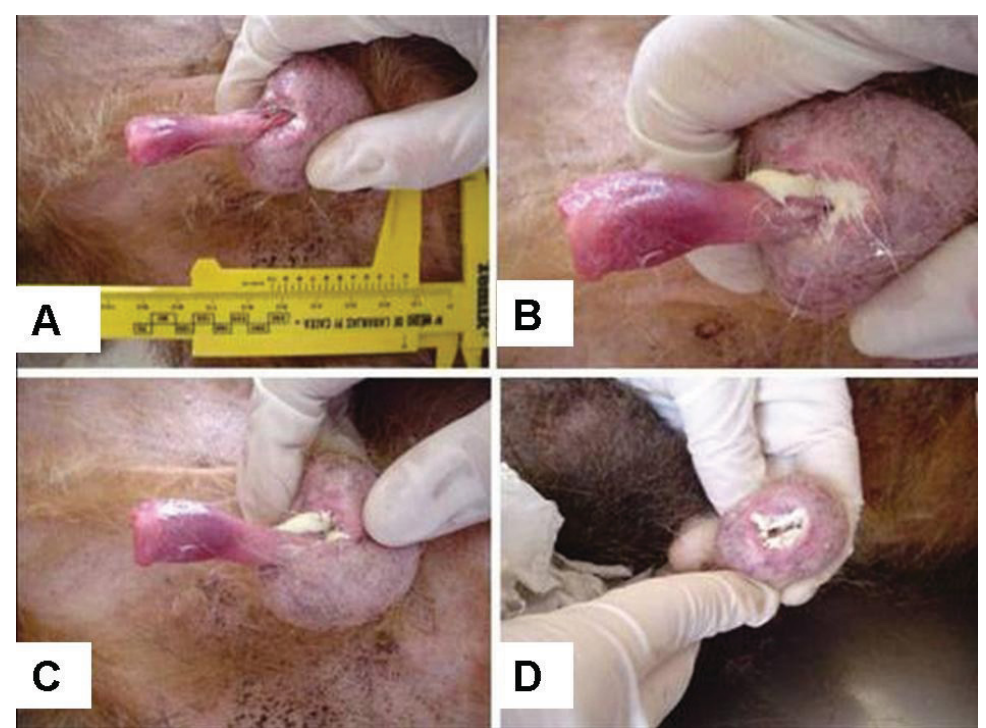

FIGURA 1: Fotografias da glândula prepucial. (A) exposição do pênis através do óstio prepucial. (B) e (C) exposição do pênis e secreção de coloração esbranquiçada e viscosa (seta cheia). (D) compressão manual da glândula com liberação de secreção (Seta fina). 
O Nasua nasua possuem a glândula prepucial, de aspecto rugoso nas bordas e na porção interna da mucosa prepucial, apresenta coloração rósea intensa, formato arredondado, semelhante a um bulbo (Figura 1) e quando seccionada apresenta aspecto lobado, com septos evidentes. O óstio prepucial apresentou-se aderido à pele e circundado por pelos. Notou-se também que a glândula produzia uma secreção esbranquiçada, viscosa, inodora para humanos e em forma de pontos. Vários óstios glandulares em forma de "chuveiro", localizada próxima ao óstio prepucial (Figura 1A, 1B, $1 \mathrm{C}$ e $1 \mathrm{D})$.

Deutsch e Puglia (1988) afirmam que comportamento de demarcação de território da capivara (Hydrochaeris hydrochaeris) é feita pela compressão da glândula prepucial, semelhante aos achados de Franciolli (2007) e em nossos estudos com quatis.

Os resultados das medidas biométricas apontam que a glândula prepucial possui média de $3,8 \pm 1,41 \mathrm{~cm}$ de largura, $3,15 \pm 0,93 \mathrm{~cm}$ de altura e $10,26 \pm 1,89 \mathrm{~cm}$ de diâmetro. As diferenças de medidas entre os indivíduos (Tabela 1) podem ser explicadas, devido às coletas serem realizadas em diferentes períodos do ano, períodos de acasalamento e também presença de mais de um macho nos recintos, o que pode modificar a quantidade de secreção da glândula, tendo em vista que estes animais são muito territorialistas, assim como já descrito por Franciolli (2007).

TABELA 1: Medidas referentes à biometria da glândula prepucial do quati.

\begin{tabular}{cccc}
\hline Indivíduo & $\begin{array}{c}\text { Largura } \\
(\mathbf{c m})\end{array}$ & $\begin{array}{c}\text { Altura } \\
(\mathbf{c m})\end{array}$ & $\begin{array}{c}\text { Circunferência } \\
(\mathbf{c m})\end{array}$ \\
$\mathbf{1}$ & 2,90 & 4,0 & 9,5 \\
$\mathbf{2}$ & 3,00 & 3,2 & 12,0 \\
$\mathbf{3}$ & 3,90 & 2,1 & 14,0 \\
$\mathbf{4}$ & 3,50 & 2,2 & 9,5 \\
$\mathbf{5}$ & 2,80 & 3,0 & 9,0 \\
$\mathbf{6}$ & 6,80 & 4,7 & 8,9 \\
$\mathbf{7}$ & 4,50 & 3,5 & 10,0 \\
$\mathbf{8}$ & 3,00 & 2,5 & 9,2 \\
\hline Média & 3,80 & 3,15 & 10,26 \\
\hline Desvio & 1,41 & 0,93 & 1,89 \\
padrão & & & \\
\hline
\end{tabular}

Constatamos que a glândula de cheiro está situada na porção interna do tegumento e na porção distal do prepúcio, próxima a glande, esta possui um revestimento de pele típica, possuindo um epitélio de revestimento e mais ao interior um tecido muscular estriado e tecido conjuntivo muito vascularizado com numerosas glândulas sebáceas (Figura 2A e 2C) do mesmo relatado por Ferreira et al. (2007), que nem sempre estão relacionadas aos pêlos, conforme afirmam Dellmann e Wrobel (1982) em seus estudos com glândulas de cheiro.

A glândula é recoberta pela pele que envolve o prepúcio, histologicamente é constituída por epitélio estratificado pavimentoso queratinizado (Figura 2C), fino, com delgada camada de queratina, abaixo do epitélio encontra-se à derme, constituída de tecido conjuntivo frouxo, que na derme papilar é denso não modelado e muito vascularizado (Figura 3A), semelhante ao achado de Dourado et al. (2001) na glândula gular no morcego da espécie Molossus molossus.

Esse tecido adentra o parênquima glandular em direção à uretra, formando septos, dividindo a glândula septos, lobos e lóbulos. Esses septos carreiam vasos por todo parênquima glandular, sendo que não foram observados ductos excretores interlobares. Os septos estenderam-se até a lâmina própria do epitélio da uretra peniana, que revelou um epitélio estratificado pavimentoso não queratinizado na região próxima ao óstio prepucial (Figura 3C). Nesta derme estão contidas várias glândulas dos tipos, sebácea e sudorípara (apócrina) associadas aos pêlos que se vertem para o meio externo (Figura 2A). Esses achados são os mesmos encontrados, na pele fina dos animais domésticos, por Banks (1991) e Stinson e Calhoun (1982).

A glândula prepucial apresentou arranjos de glândulas em forma de "folículos ramificados", e a porção tubular secretora das glândulas sudoríparas se abriram para pele (Figuras 3D, 3E e 3F).

Dourado et al. (2001) relatam que aspectos histológicos apontam para um padrão que se assemelha muito ao apresentado pelas glândulas secretoras das glândulas sebáceas de outros mamíferos, comprovamos em nossos estudos que a glândula prepucial é do tipo tubuloalveolar, sendo que cada alvéolo (porção secretora) se assemelha a um folículo com ramificações 

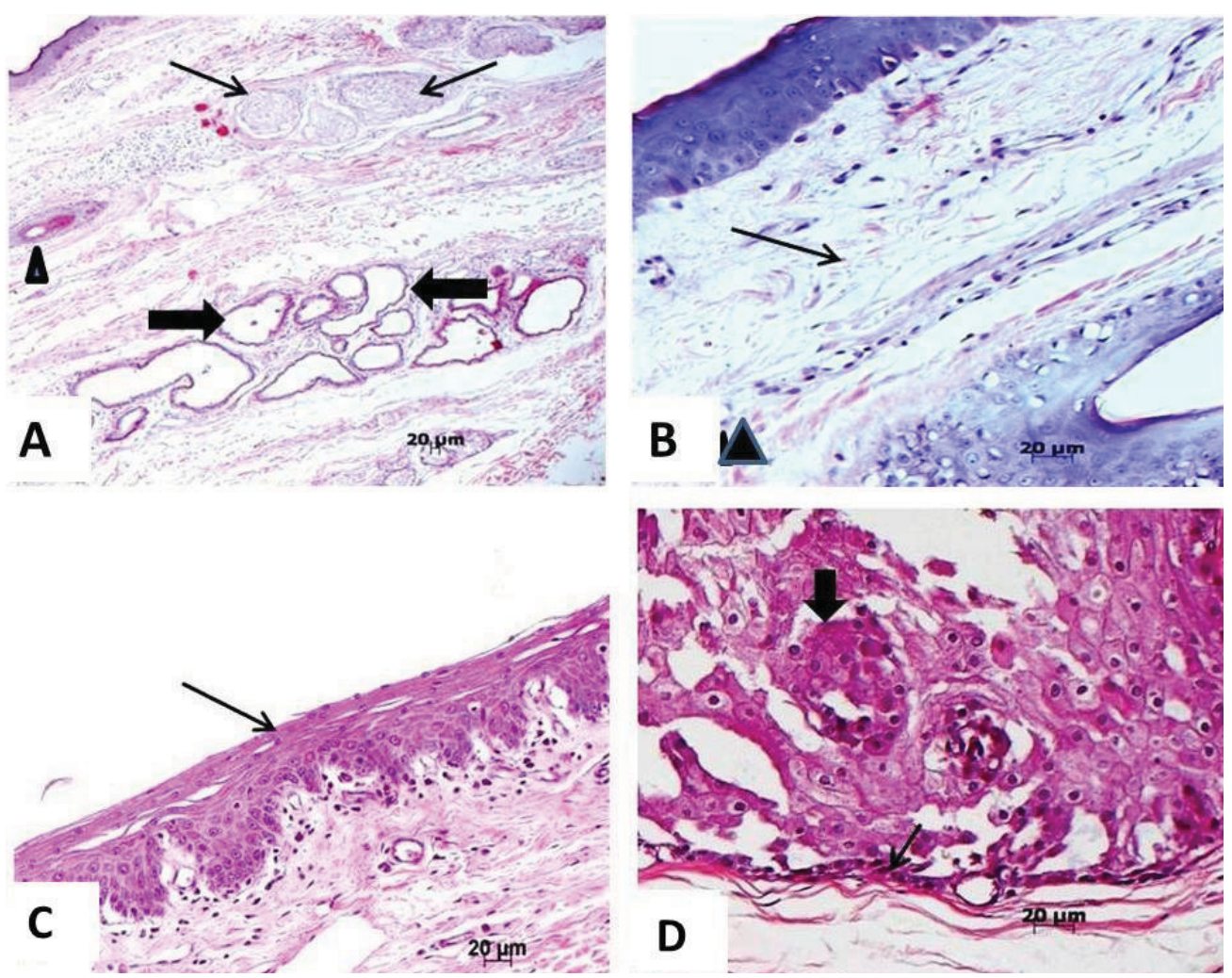

FIGURA 2: Fotomicrografia da glândula prepucial do Nasua nasua. (A) Observar glândulas sebáceas (seta), folículo piloso (cabeça seta) e glândulas sudoríparas (seta cheia). (B) Músculo estriado (seta) e tecido conjuntivo vascularizado (cabeça seta), importantes na contração desta glândula. (C) Epitélio de revestimento da pele que reveste a glândula (seta) e em (D) células maduras secretoras

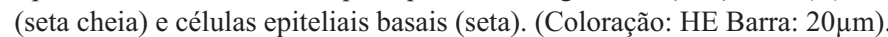

que se dirigem para o centro. Na base desses alvéolos existe um epitélio simples cúbico constituído por células basais, que em alguns locais se aglomeram formando um conjunto de células com pigmentação mais escura (Figura 2D). Essas células basais são células que dão origem através de mitose às células secretoras que formam o parênquima glandular. Nos alvéolos estão presentes células com características de secreção de gordura semelhante às glândulas sebáceas e as células esteroidogênicas do ovário.

Todos os animais estudados apresentavam secreção nos ductos glandulares (Figuras 4A), conforme Costa et al. (2007), quando citam que as glândulas sudoríferas das regiões púbicas e perianais dos Callithrix jacchus e kuhlli possuíam muitas secreções na luz dos túbulos e no ápice celular, indicando uma grande atividade glandular.
Células grandes com núcleos bem arredondados ocupam certas regiões do tecido analisado (Figura 4), e possuem citoplasma mais claro. Quando próximo ao epitélio o núcleo dessas células aparenta um tamanho maior que o núcleo das outras células distantes do epitélio devido a serem células secretoras possuem também um citoplasma claro (Figura 4D). Essas glândulas são do tipo holócrinas, pois logo ao centro dos lóbulos há um acúmulo de debris celulares, proveniente da ruptura de sua membrana e liberação de seu conteúdo (Figura 2A, 2B e 4A). Observamos que há ductos intralobulares (Figura 4C) nessa glândula com abertura para a parte externa, levando assim a substância secretada pelas células para o meio externo.

Costa et al. (2007) relatam que a glândula dos Callithrix jacchus e Callithrix kuhlli são glândulas superficiais e estão diretamente ligadas ao meio externo 

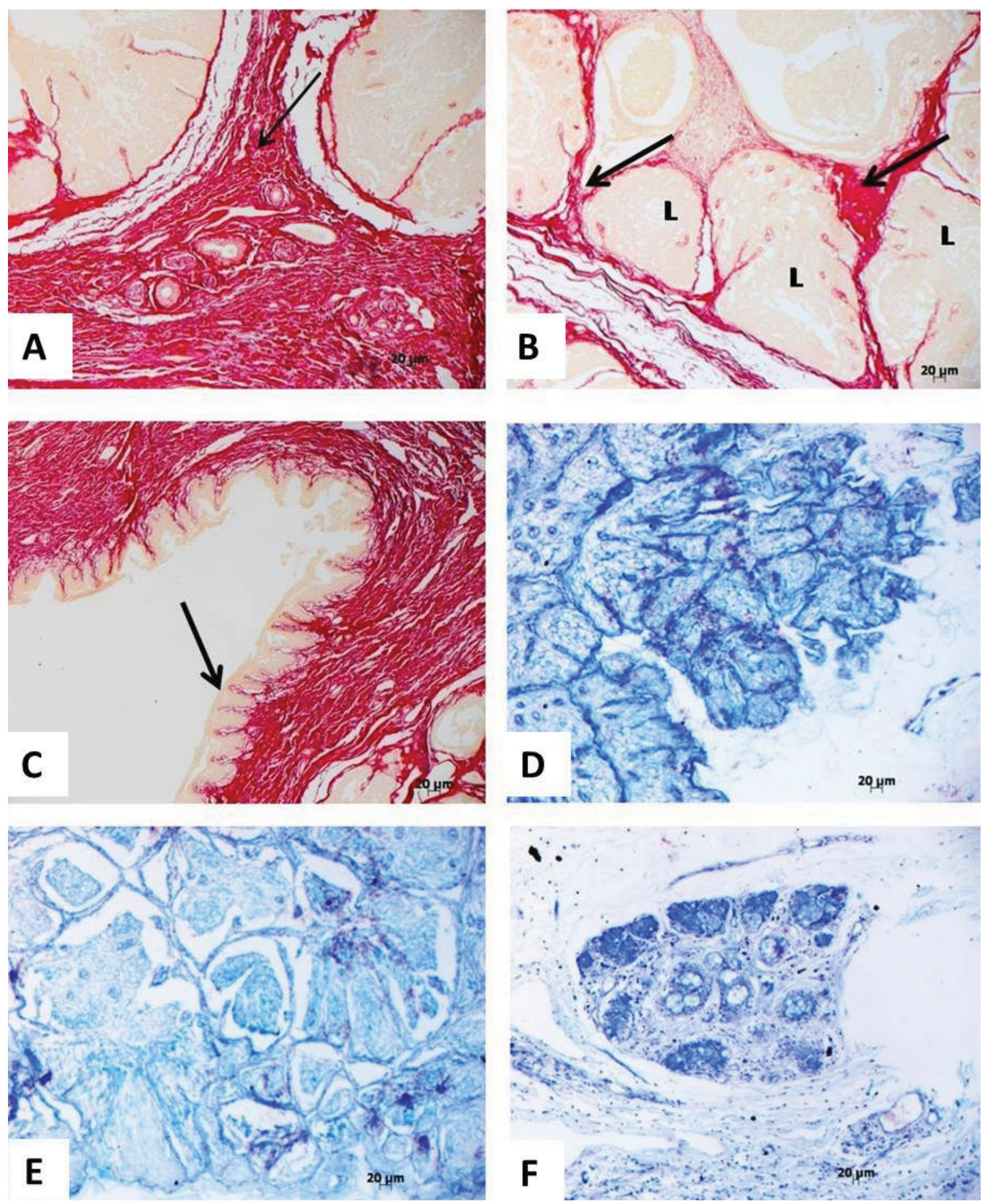

FIGURA 3: Fotomicrografia da glândula prepucial do Nasua nasua. (A) Tecido conjuntivo que circunda toda a glândula (seta). (B) Tecido conjuntivo (seta) dividindo a glândula em lóbulos (L). (C) Epitélio da uretra estratificado pavimentoso (seta). (D) e (E) Notar arranjo da glândula em forma de "folículos ramificados". (F) Porção tubular secretora das glândulas sudoríparas que se abrem para pele. (Coloração: Picrossirus e Azul de Toluidina; Barra: $20 \mu \mathrm{m})$. 

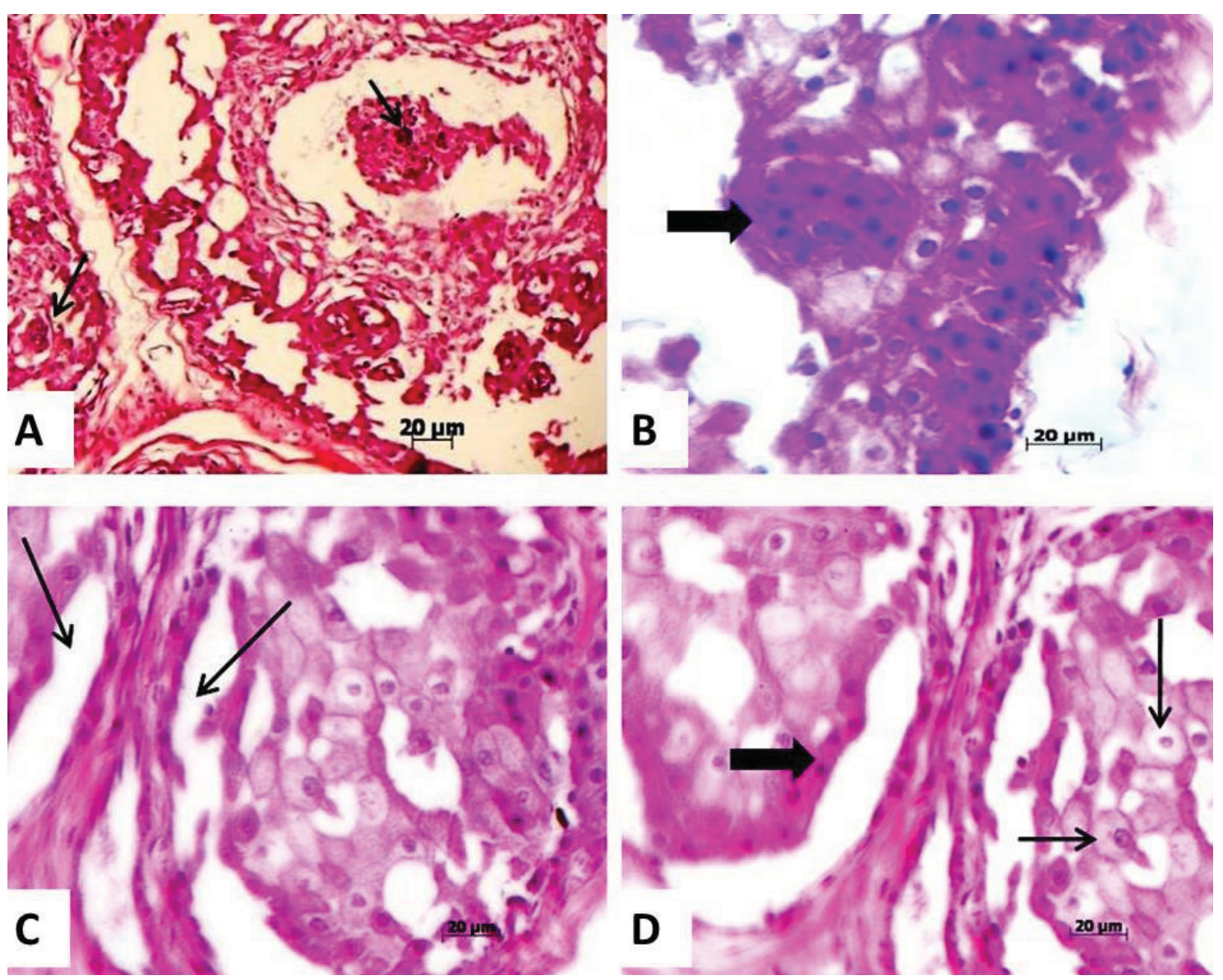

FIGURA 4: Fotomicrografia da glândula prepucial do Nasua nasua. (A) Secreção na luz dos alvéolos com debris celular (setas) indicando secreção holócrina. (B) Células epiteliais formando um grupo celular dentro do parênquima (seta). (C) Parênquima glandular e células epiteliais cúbicas formando um ducto intralobular (seta). (D) Células secretoras exuberantes com núcleos redondos centrais (seta), citoplasma claro caracteristicamente espumoso. Observar epitélio

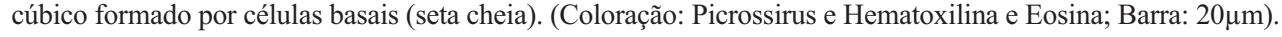

nos folículos pilosos, como uma abertura em cada folículo, diferente ao visualizado nos quatis, no qual se observa uma glândula cuja secreção conflui para ductos maiores e estes para os óstios específicos da glândula no ápice prepucial.

Conclui-se então que: a glândula prepucial é morfologicamente tubuloalveolar, possui secreção holócrina, bem desenvolvida em todos os animais estudados, e as diferenças biométricas encontradas não foram significativas podendo estar relacionadas ao período de coleta e maturidade sexual dos indivíduos. Esta estrutura anatômica é de especial relevância no Nasua nasua devido ao seu comportamento reprodutivo, demarcação de território e sinalização.

\section{Agradecimentos}

À UNIFEOB pelo incentivo à produção científica, à FAPESP por permitir a dedicação à pesquisa em período integral do autor principal.

\section{Referências}

BANKS, W. J. Histologia Veterinária Aplicada. 2 ed. São Paulo: Manole, 1991. 560 p.

BEISIEGEL, B. M. Notes on the quati, Nasua nasua (Carnívora: Procyonidae) in na Atlantic Forest area. Brazilian Journal of Biology, São Carlos, v. 61, n. 4, p. 689-692, 2001.

COSTA, G. M.; FRANCIOLI, A. L. R.; MANCANARES, C. A. F.; LIMA, M. G.; AMBRÓSIO, C. E.; MIGLINO, M. A.; KFOURY JR., J. R.; PORFIRIO, S.; CAVALHO, A. F. Análise 
comparativa das glândulas cutâneas de cheiro do sagui de tufobranco (Callithrix jaccus) e do sagui de tufo-preto (Callithrix kuhlii) (Callithrichidae, Primates). Biotemas, Florianópolis, v. 20, n. 2, p. 65-72, 2007.

DELLMANN, H. D.; WROBEL, K. H. Sistema reprodutor masculino. In: DELMANN, H. D; BROWN, E. M. (Eds). Histologia Veterinária. Rio de Janeiro: Guanabara Koogan, 1982. p. 233-253.

DEUTSCH, L. A.; PUGLIA, L. R. Capivara: os animais silvestres - proteção, doenças e manejo. Rio de Janeiro: Globo Rural, 1988. $191 \mathrm{p}$.

DOURADO, D. M.; JARDIM, M. I. A.; SOUZA, C. C.; BUCCINI, D. F.; TADDEI, V. A.; PUCHERIO, A.; MINIGUELLI, M.; SOUZA, H. A. Estudo histológico e histoquímico da glândula gular da espécie de morcego Molossus molossus. Ensaio e Ciência, Campo Grande, v. 5, n. 2, p. 141-149, 2001.

ELLENPORT, C. R. Aparelho urogenital do carnívoro. In: GETTY, R. (Ed.). Sisson e Grossman. Anatomia dos animais domésticos. v. 2. 5. ed. São Paulo: Guanabara Koogan, 1986. p. 1482-1493.

FERREIRA, B. F.; BURITY, C. H. F.; PISSINATTI, A. Histologia do tegumento em Cebus robustus (SILVA JR., 2001) e Cebus xanthosternos (Wied-Neuwied, 1826): Cativos, Cebidae-Primates. Saúde e ambiente, Duque de caxias, v.2, n.1, p. 50-67, jan.-jun. 2007.
FRANCIOLLI, A. L. R.; COSTA, G. M.; MANÇANARES, C A. F.; MARTINS, D. S.; AMBRÓSIO, C. E.; MIGLINO, M. A.; CARVALHO, A. F. Morfologia dos órgãos genitais masculinos de quati (Nasua nasua, Linnaeus 1766), Biotemas, 20 (1): 27-36, 2007.

HERRERO, Y. J.; ROSELL, C.; FERNÁNDEZ-LLARIO P.; El jabalí (Sus scrofa Linnaeus, 1758). Galemyz, Barcelona, v. 13, n. 2, p. 1-25, 2001.

HICKMAN JR., J. P.; LARSON, A.; ROBERTS, L. S. Princípios Integrados de Biologia. Zoologia. 11 ed. Rio de Janeiro: Guanabara Koogan, 2004. 872 p.

INTERNATIONAL COMMITTEE ON VETERINARY GROSS ANATOMICAL NOMENCLATURE. Nomina Anatomica Veterinaria. 5. ed. New York: World Association on Veterinary Anatomist, 2005. 165 p.

JUNQUEIRA, L. C.; CARNEIRO. J. Histologia básica. 11 ed. Rio de Janeiro: Guanabara Koogan, 2008. 524 p.

STINSON, A. L. M.; CALHOUN, M. L. Epitélio. In: DELMANN, H. D.; BROWN, E. M. (Ed.). Histologia Veterinária. Rio de Janeiro: Guanabara Koogan, 1982. p. 20-35.

TOLOSA, E. M. C.; RODRIGUES, C. J.; BEHMER, O. A.; FREITAS NETO, A. G. Manual de Técnicas para Histologia Normal e Patológica. 2. ed. São Paulo: Manole, 2003. 331 p.

ZELLER, U. Mammalian reproduction: origin and evolutionary transformations. Zoologischer Anzeiger, Berlin, v. 238, n. 1-2, p. 117-130, 1999. 